\title{
Relação Campo-Cidade e dinâmica Econômica nos municípios da APA do Rio Machado-MG
}

\section{Countryside-city and dynamic economic relations in the municipalities in the area of environmental protection of Machado river - MG}

Flamarion Dutra Alves

Doutor em Geografia e docente do Programa de Pós-graduação em Geografia da Universidade Federal de Alfenas - MG

dutrasm@yahoo.com.br

Gil Carlos Silveira Porto Doutor em Geografia e docente do curso de Geografia da Universidade Federal de Alfenas - MG porto.gil@gmail.com

Daniel Hideki Bando Doutor em Geografia e docente do curso de Geografia da Universidade Federal de Alfenas - MG danielhban@gmail.com

Tiago Marini Ribeiro Discente do curso de Geografia Licenciatura da Universidade Federal de Alfenas - MG $\underline{\text { tiago.mariniribeiro@yahoo.com.br }}$

Matheus de Oliveira Silva Discente do curso de Geografia Bacharelado da Universidade Federal de Alfenas - MG matheus-sjc@hotmail.com.br

\begin{abstract}
Resumo
Este artigo trata do estudo da dinâmica econômica e a relação campo-cidade nos municípios da APA do Rio Machado, sul de Minas Gerais. A pesquisa procurou entender o comportamento das atividades agropecuárias nos municípios, bem como os processos urbanos no contexto desses municípios, principalmente de Alfenas, como cidade média que polariza boa parte da região em questão. Foram utilizados dados secundários para caracterização da área de estudo, bem como aplicação de entrevistas nas áreas rurais e urbanas para analisar a relação dessas populações com o rio Machado. Pôde-se considerar que a dinâmica socioeconômica está muito atrelada atividades agropecuárias, sobretudo o café, e a cidade de Alfenas exerce uma função de centro polarizador do setor terciário.
\end{abstract}

Palavras-chave: Campo-cidade, Economia, Agricultura, Cidades pequenas, Cidade média.

\begin{abstract}
This article deals with the study of economic dynamics and the countryside-city relationship in APA districts of Rio Machado, southern Minas Gerais. The research sought to understand the behaviour of agricultural activities in the municipalities, as well as the urban processes in the context of these municipalities, mainly Alfenas, as a middle-sized city that polarizes much of the region in question. Secondary data were used to characterize the study area, as well as the application of interviews in rural and urban areas, to analyze the relationship between these populations and the Machado River. It could be considered that the socioeconomic dynamics are closely linked to agricultural activities, especially coffee, and the city of Alfenas serves as a polarizing centre for the tertiary sector.
\end{abstract}

Keywords: Countryside-city, Economy, Agriculture, Small Towns, Middle City. 


\section{INTRODUÇÃO}

O estudo socioeconômico regional apresenta-se complexo, à medida que envolve uma diversidade de municípios e realidades locais, ainda mais, considerando uma delimitação a partir de uma bacia hidrográfica, no contexto de uma Área de Proteção Ambiental (APA). A partir dessa realidade, o estudo a seguir apresenta como objetivos analisar a dinâmica econômica dos municípios pertencentes a APA do rio Machado, sul de Minas Gerais (Figura 1), bem como discutir a relação campo-cidade e suas atividades econômicas na APA do rio Machado, e por fim, verificar o papel da cidade média de Alfenas no contexto econômico regional.

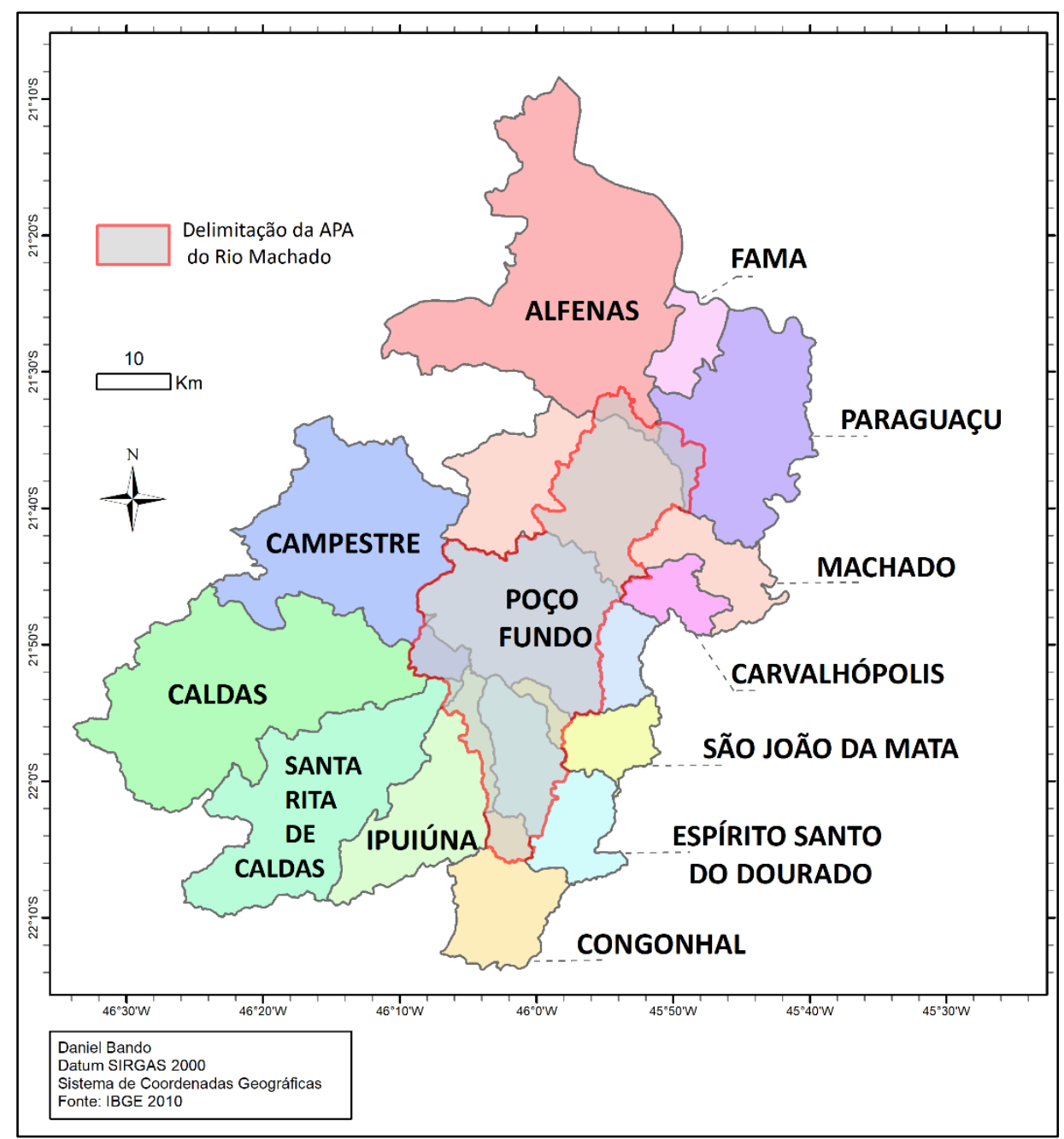

Figura 1 - APA do Rio Machado e municípios que a integram.

O estudo socioeconômico em áreas de proteção ambiental, é importante para o detalhamento das relações sociais existentes, cotidiano e modos de vida, além de caracterizar as atividades econômicas que demandam o uso e intensidade ambiental. Faz-se necessário, analisar esse quantitativo e área plantada, nas atividades agropecuárias, assim, como as atividades econômicas situadas no espaço urbano. 


\section{METODOLOGIA}

A análise socioeconômica de uma área correspondente a uma bacia hidrográfica, e por sua vez a uma área de proteção ambiental, se constitui num desafio para os geógrafos uma vez que o limite da área drenada não corresponde os limites das unidades municipais. Desse modo, essa foi a escala selecionada para coleta de dados, considerando que as características populacionais e econômicas ali presentes se mantem nas áreas drenadas pelos rios que formam a bacia hidrográfica do rio Machado. Definindo esse critério, a pesquisa foi dividida em três etapas.

A primeira abarcou a coleta de dados no Instituto Brasileiro de Geografia e Estatística (IBGE), nas plataformas SIDRA e IBGE CIDADES, além de buscas no site Atlas Brasil, Fundação João Pinheiro (FJP) e Instituto de Pesquisa Econômica Aplicada (IPEA). As informações são oriundas dos censos agropecuários (2006) e demográfico (2010) do IBGE e abarcam desde a distribuição da população residente nas áreas rurais e urbanas, bem como abarcando o Produto Interno Bruto e produção agrícola de cada unidade municipal, por exemplo.

O agrupamento das informações de cada município em tabelas e figuras foi feito na segunda etapa da pesquisa, possibilitando identificar características gerais da população residente, bem como especificidades populacionais e econômicas que possuem.

Num terceiro momento da pesquisa realizou-se trabalho de campo objetivando observar elementos da paisagem percorrida, bem como situações que contribuíssem para caracterizar o modo de vida da população residente na área da APA. O trabalho de campo também possibilitou a realização de entrevistas abertas, com intuito de conhecer melhor as trajetórias de vida dos moradores residentes na bacia do rio Machado, sua organização social e a percepção que possuem dos rios por eles utilizados. Foram realizados dois trabalhos de campo; o primeiro ocorreu em 21 de fevereiro de 2018, onde se realizaram 7 (sete) entrevistas em bairros rurais dos municípios de Poço Fundo e Ipuiuna, na tentativa de entender a importância e uso do rio junto aos agricultores familiares. O segundo ocorreu no dia 07 de maio e percorreu os bairros do Centro, Santo Antônio 1 e Córrego Fundo no município de Machado. Nessa última oportunidade foram realizadas 14 (quatorze) entrevistas, e a escolha desses bairros se deu pela ocupação urbana junto ao leito do rio Machado e seus afluentes, ou seja, essa etapa visa compreender como a população urbana convive com o rio.

Importante destacar inicialmente, o quantitativo populacional dos municípios da APA do rio Machado (Tabela 1), pois assim partimos da compreensão demográfica para a análise socioeconômica 
Tabela 1 - População dos municípios da APA Rio do Machado, 2010.

\begin{tabular}{lc}
\hline \multicolumn{1}{c}{ Municípios } & População Residente \\
\hline Fama & 2.350 \\
São João da Mata & 2.731 \\
Carvalhópolis & 3.341 \\
Espírito Santo do Dourado & 4.429 \\
Santa Rita de Caldas & 9.027 \\
Ipuiúna & 9.521 \\
Congonhal & 10.468 \\
Caldas & 13.633 \\
Poço Fundo & 15.959 \\
Paraguaçu & 20.245 \\
Campestre & 20.686 \\
Machado & 38.688 \\
Alfenas & 73.774 \\
TOTAL & $\mathbf{2 2 4 . 8 5 2}$ \\
\hline
\end{tabular}

Com base nos dados do IBGE de 2010, os municípios pertencentes a APA do rio Machado totalizam 224.852 habitantes, Alfenas apresenta características de uma cidade média, Machado tem traços de uma cidade pequena em transição para média, ou como aponta o REGIC (2007) um Centro de Zona, e os demais 11 municípios tem porte e dinâmicas de uma cidade pequena. (SPOSITO, 2007; CORRÊA, 2007; REGIC, 2007)

\section{INTERAÇÕES ESPACIAIS ENTRE CAMPO E CIDADE}

Partimos do entendimento de Alves (2018) sobre o estudo de cidades no sul de Minas Gerais "Discutir o espaço regional sul mineiro é antes de tudo, um estudo da relações rurais-urbanas e das redes urbanas compostas por cidades pequenas e médias.” (2018, p.107), ou seja, é inseparável a dinâmica campo-cidade no contexto regional no sul do Estado de Minas Gerais. Nesse sentido, partese para a análise das interações espaciais, sempre levando em consideração o campo e cidade.

As interações espaciais das escalas articulam-se a uma totalidade - a globalidade social que carrega uma gênese e um movimento. Nesse contexto da rede urbana, Corrêa (1997) define as interações espaciais:

As interações espaciais constituem um amplo e complexo conjunto de deslocamento de pessoas, mercadorias, capital e informação sobre o espaço geográfico. Podem apresentar maior ou menor intensidade, variar segundo a frequência de ocorrência e, conforme a distância e direção, caracterizar-se por diversos propósitos e se realizar através de diversos meios e velocidades. (CORRÊA, 1997. p. 279).

Procuramos assim articular as partes da análise a um processo global de reprodução da sociedade como um todo. Isso vale também para a abordagem da cidade média e pequena, que pode ser entendida em sua dinâmica. Ou para Corrêa (2007, p. 26), “A cidade média pode ser, assim, como um estado transitório. As implicações disso podem ser amplas para mais o estabelecimento de um conceito de cidade média".

Essa dinâmica e produção do espaço é entendida por Milton Santos (2014, p.18) como: 
O estudo das interações entre os diversos elementos do espaço é um dado fundamental da análise. Na medida em que a função é ação, a interação supõe interdependência funcional entre os elementos. Através do estudo das interações, recuperamos a totalidade social, isto é, p espaço como um todo e, igualmente, a sociedade como um todo. Pois cada ação não constitui um dado independente, mas um resultado do próprio processo social.

O autor explica que para entender o espaço, é necessário compreender os movimentos e ações ao longo do tempo, as mudanças das formas e funções, nesse re-arranjo na organização do espaço.

Os movimentos da sociedade, atribuindo novas funções e formas geográficas, transforma a organização do espaço, criam novas situações de equilíbrio e ao mesmo tempo novos pontos de partida para um novo movimento. Por adquirirem uma vida, sempre renovada pelo movimento social, as formas - tornadas assim formas-conteúdo - podem participar de uma dialética com a própria sociedade e assim fazer parte da própria evolução do espaço. (SANTOS, 2006, p.106).

Acerca do conceito de cidade média, não nos aprofundaremos aqui, e apoiado em Corrêa (2007), procura-se a classificação desta numa particular combinação entre tamanho demográfico, funções urbanas e organização do espaço intraurbano. Expressando uma dialética entre quantidade e qualidade em que o tamanho da população resulta numa maior complexidade da divisão social e territorial do trabalho e das classes sociais.

\begin{abstract}
Quanto maior o tamanho demográfico, maior a dimensão do espaço intra-urbano, expressa pela distância entre o centro e a periferia da cidade, assim como mais complexa será a organização desse espaço intra-urbano. Em razão das distâncias viabiliza-se em grande parte, uma maior divisão econômica do espaço, submetido a um mais significativo processo de descentralização, origem dispersa e formação de núcleos de atividades derivados de economias de aglomeração, distantes do centro. Maior o tamanho demográfico e mais complexas as atividades econômicas, suscitando maior fragmentação do tecido social, mais complexa será a projeção espacial das classes sociais e suas frações, gerando uma mais complexa divisão social do espaço, com áreas sociais mais diversificadas (CORREA, 2007, p. 24).
\end{abstract}

A dificuldade estaria em tentar captar no crescimento da cidade pequena a mudança qualitativa das relações espaço temporais que marcaria sua passagem para a categoria de cidade média e, do mesmo modo, quando do crescimento da cidade média a sua mudança qualitativa e sua transformação em cidade grande.

Chama-se a atenção ainda para a necessidade de relativização dos conceitos de centro e de periferia, em virtude da maior complexidade das relações socioespaciais, uma abordagem dualística entre centro e periferia deixa de explicar as transições e as continuidades entre esses dois espaços, além da formação de novas centralidades, seja na escala local seja na constituição de uma rede urbana complexa, ou em escalas mais amplas. 
Caberia indagar o que há de novo na estruturação das cidades médias no sul de Minas? Sposito (2007, p. 235-237) também discorre sobre a configuração de novas formas de articulação das cidades nas redes urbanas, que classifica de relações transversais, quando cidades de uma rede articulam-se com outras redes. Em trabalho sobre as cidades médias, a autora sustenta a necessidade de relacionar os estudos nas escalas intraurbana e interurbana (região). Frente à complexificação das relações, propõe a relativização dos conceitos de centro e periferia, nas diversas escalas geográficas (intraurbana, regional, nacional e internacional).

Em relação ao espaço intraurbano, "a observação das novas formas de produção, propriedade e apropriação do espaço urbano, expressas pela constituição de uma cidade descontínua ou dispersa" (SPOSITO, 2007, p. 249). A autora aponta para o aumento das desigualdades e fragmentações socioespaciais:

Igualmente, nota-se a tendência para a fragmentação socioespacial, sem ainda atingir a tessitura política das relações, como se nota nas metrópoles, ainda que se tornem mais complexas as estruturas de distribuição das atividades econômicas e das funções sociais das cidades, com destaque para as residenciais, gerando enclaves de uso exclusivo em cidades médias (SPOSITO, 2007, p. 244).

Não obstante a importância de levarmos mais em consideração as escalas espaciais, no caso de uma análise comparativa entre cidades, cujo tempo de estruturação são bem diferentes, também é fundamental considerar as escalas temporais distintas em seus processos de estruturação urbana.

No caso da APA do rio Machado há uma predominância de aglomerados rurais e poucos núcleos urbanos, como mostra a figura 2.

Pensando a ruralidade nos municípios sul mineiros, Alves e Vale (2013, p.39) destacam “nesses lugares o rural determina o ritmo de vida da população rural e urbana, além de manter as questões culturais e de identidade territorial presentes independente do grau de urbanização", ou seja, a dinâmica econômica está interligada ao modo de vida e identidade regional.

Aliado a questão urbano-regional, o espaço agrário apresenta elementos da produção do espaço importantes para a análise regional. A região sul de Minas Gerais é caracterizada por apresentar um relevo montanhoso com altitudes entre 600 a 1200 metros, e um clima ameno e propício para a produção do café tipo arábica, conforme aponta o estudo de Silva et.al (2004). A aptidão agrícola para a cafeicultura no estado de Minas Gerais, e sobretudo, a região sul mineira é destacada por Evangelista, Carvalho e Sediyama (2002, p.446)

No Brasil, as boas regiões produtoras de café estão localizadas onde ocorrem mais de 150 mm de chuva por mês, no período de florescimento, formação e maturação dos frutos, que compreende os meses de outubro a março nas regiões produtoras do Estado de Minas Gerais, ou seja, o período de renovação de galhos e folhas. 


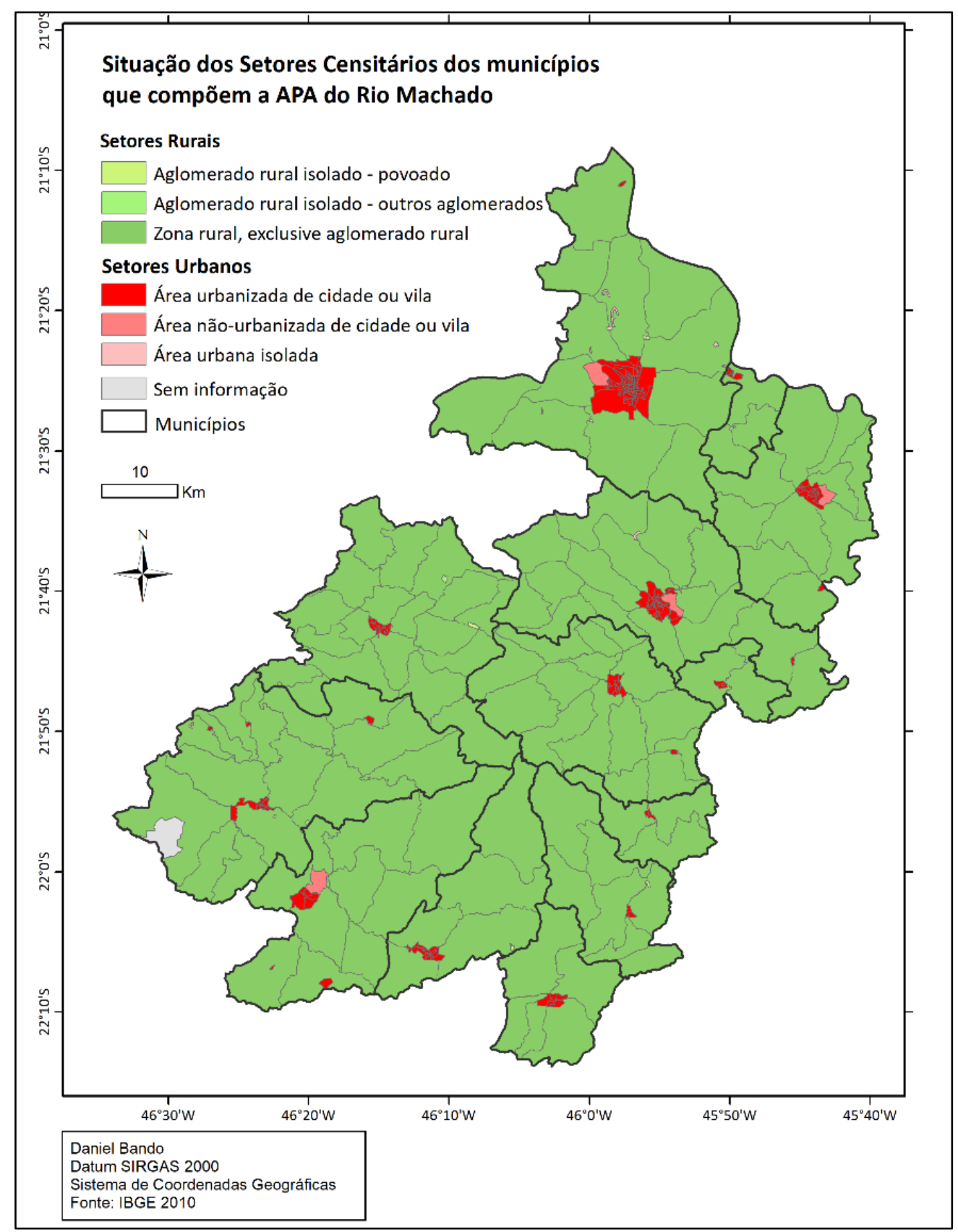

Figura 2 - Aglomerados urbanos e rurais nos municípios da APA do rio Machado-MG.

Além da questão ambiental que favorece a atividade cafeeira é decisivo o papel da estrutura social na produção e organização do espaço nessa região. De acordo com Filetto e Alencar (2001) houveram três etapas no processo de ocupação e expansão da atividade cafeeira no sul de Minas Gerais, que modelaram e configuraram o território:

O primeiro período refere-se à introdução e expansão do cafeeiro no sul mineiro, no início e durante o século XIX. O segundo período refere-se a uma nova expansão no final do século XIX, acoplada à expansão no oeste paulista e ainda apresenta elementos históricos referentes às primeiras décadas do século XX. O terceiro período refere-se à formação do complexo agroindustrial do café sul mineiro, a partir da década de 1970 (FILETTO; ALENCAR, 2001, p.2). 
O último momento, iniciado pós 1970, marca o processo denominado Revolução Verde ou a Modernização da Agricultura no Brasil, este momento foi caracterizado pelo acréscimo de insumos químicos e biológicos no processo produtivo, incremento de tecnologias no plantio, além de mecanizar algumas etapas da produção agrícola.

Entretanto, houveram duas questões centrais no sul de Minas para que não houvesse a territorialização do capital e a modernização agrícola plena, como houve no Centro-Oeste com a soja ou no interior paulista com a cana-de-açúcar por exemplo. Essas questões são a estrutura fundiária, marcada pelos minifúndios e pequenas propriedades dificultando a inserção do produtor ao sistema moderno e capitalista, devido à escassez de área, e o outro fator e o relevo acidentado que dificulta a inserção da mecanização agrícola, fazendo com que a mão de obra seja feita por migrantes que vem de outras regiões de Minas Gerais e do Nordeste nos períodos da colheita.

Essas duas questões são referidas por Filetto e Alencar (2001) como variáveis para a permanência de uma estrutura social tradicional, diferente das chamadas "cidades do agronegócio" onde as relações socioeconômicas são mais dinâmicas e os pequenos proprietários foram abreviados territorialmente pelas médias e grandes propriedades.

\begin{abstract}
As características desta estrutura tradicional se consubstanciam no Sul de Minas por meio de certos aspectos típicos, como o caráter personalista das relações sociais, caracterizando um tipo de relacionamento primário. O longo período em que o café está presente no sul mineiro, sem sofrer uma ruptura séria de sua estrutura produtiva levou à formação da estrutura tradicional. Outra característica desta estrutura tradicional é a falta de especialização, ou seja, a mescla de funções entre as atividades. Embora menos marcante do que em outras regiões, esses fatores apontam para uma cafeicultura permeada de valores e costumes, onde, apesar da industrialização e do surto de urbanização, a vinculação rural da população, quer por sua origem, quer por sua cultura, ainda não desapareceu. (FILETTO; ALENCAR, 2001, p.8)
\end{abstract}

Minas Gerais é hoje o principal produtor de café no Brasil, responsável por mais de $50 \%$ dos grãos, conforme já apontava o estudo de Ormond, Paula e Faveret Filho (1999, p.31) "Minas Gerais é o esteio da produção nacional de café, sendo responsável, a partir de 1994, por uma produção que varia entre $45 \%$ e $50 \%$ da safra brasileira e aumentando sua participação. Teve uma taxa anual de crescimento da produção de 3,4\%." E nesse contexto, o Sul de Minas produz 25\% do total de café brasileiro, sendo uma região latamente integrada ao mercado mundial e isso tem impacto na organização da rede de cidades sul-mineiras.

Dessa forma, entender a dinâmica socioespacial numa escala regional é importante para o estudo e comportamento das cidades e de suas influências, todavia a escala intraurbana pode desvendar os problemas e consequências dessa dependência regional e/ou nacional ou ainda mostrar processos de desenvolvimento, segregação ou estagnação. 


\section{QUADRO SOCIOECONÔMICOS NA APA DO RIO MACHADO-MG}

Os municípios nos quais se distribuem a APA do Rio Machado se localizam numa das regiões mais desenvolvidas, do ponto de vista econômico e social, do estado de Minas Gerais. Desde o século XIX o processo de ocupação do solo e desenvolvimento da agricultura se estabeleceu, aspecto que foi fortalecido pela comunicação que desde muito cedo se estabeleceu com a cidade de São Paulo, primeiro por estradas, depois por ferrovia e hoje pela rodovia Fernão Dias.

Em função da proximidade com os grandes centros urbanos e econômicos do País, bem como por aspectos próprios da sociedade local, a população dos municípios em questão possui significativa participação de sua população nas atividades econômicas no campo e nas cidades.

Em termos relativos, conforme a figura 3, Campestre é o município que apresenta o maior índice de população economicamente ativa ocupada em relação a sua população total (cerca de $73 \%$, ou seja, 11.000 pessoas). Em contraponto, Paraguaçu é a unidade municipal que possui o maior índice da população economicamente inativa (cerca de 28,4\%, ou seja, 4.225 pessoas). Já Alfenas, é o município que apresenta os melhores PIB e PIB per capita. Esse último município ainda apresenta uma taxa de $68,4 \%$ da população como economicamente ativa, $25,1 \%$ economicamente inativa e cerca de 6,6\% economicamente ativa desocupada. Em linhas gerais percebe-se que os municípios analisados possuem expressiva população que realiza algum tipo de atividade remunerada, fato que pode expressar o dinamismo econômico regional.

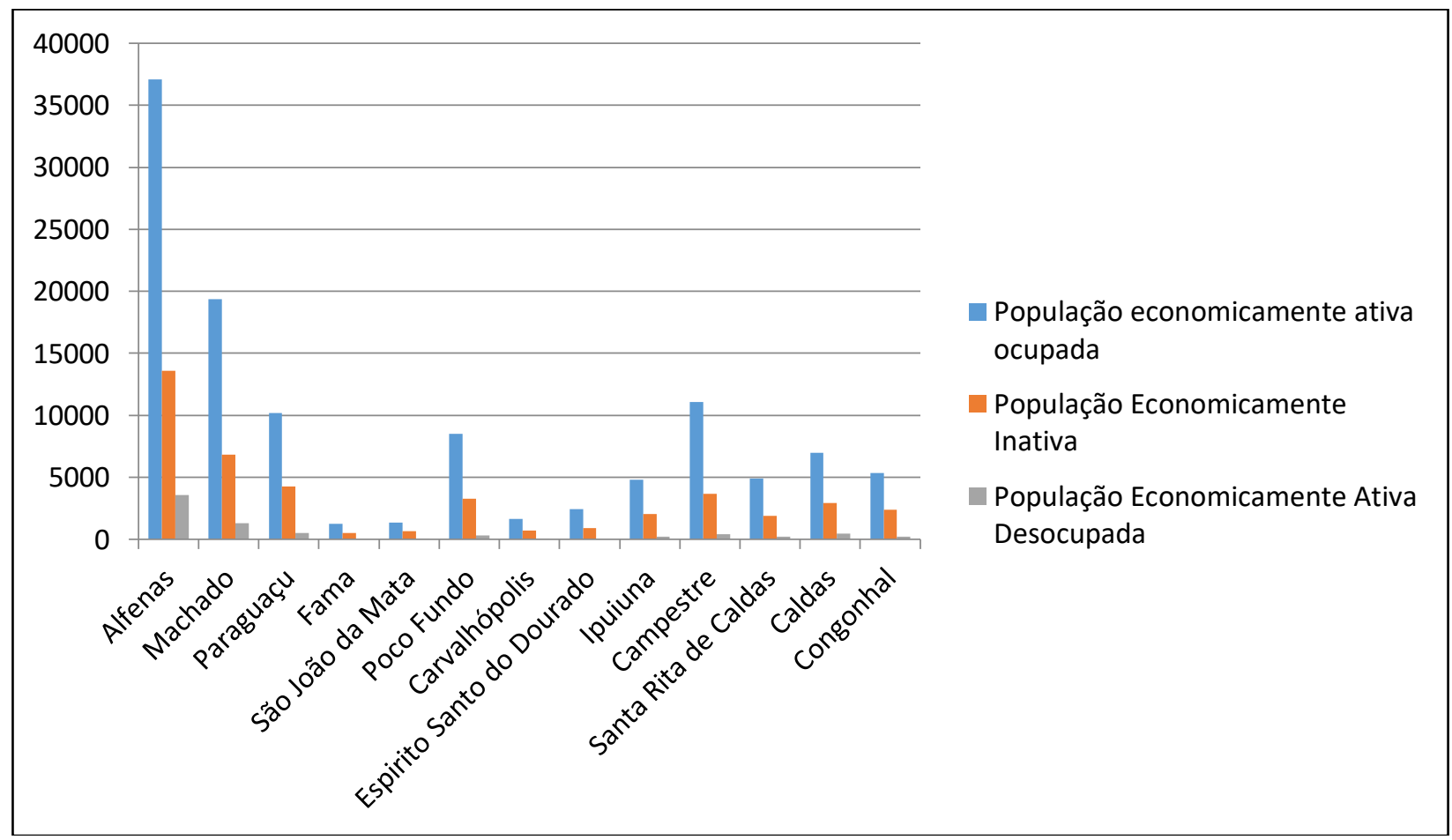

Figura 3 - Situação da população economicamente (ativa e inativa) da APA do Rio Machado, 2014.

Fonte - PNUD, Ipea, FJP. 
Outro indicador que revela a importância das economias locais para o Sul de Minas é o montante do Produto Interno Bruto de cada unidade municipal. Conforme nota-se na tabela 2, Alfenas é o município que possui o PIB mais alto entre os municípios da APA do Rio Machado, cerca de R\$ 1.735.121,00. Em segundo vem Machado, que possui um PIB de $\mathrm{R} \$ 765.137,00$. A municipalidade que possui menor PIB é Fama, que contabiliza R \$30.965,00. A discrepância entre o PIB do município mais populoso e os demais produzidos pelas demais municipalidades sugere que Alfenas exerce um poder de atração econômica em relação às demais unidades territoriais, dimensão da organização da rede urbana sul-mineira que tem Alfenas como uma importante centralidade, como já foi discutido anteriormente.

Tabela 2 - PIB dos municípios da APA do Rio Machado, 2014.

\begin{tabular}{lr}
\hline \multicolumn{1}{c}{ Municípios } & $(\mathbf{R} \mathbf{\text { ) }}$ \\
\hline Alfenas & $1.735 .121,00$ \\
Caldas & $197.721,00$ \\
Campestre & $274.688,00$ \\
Carvalhópolis & $42.719,00$ \\
Congonhal & $147.860,00$ \\
Espírito Santo do Dourado & $61.704,00$ \\
Fama & $30.965,00$ \\
Ipuiúna & $123.078,00$ \\
Machado & $765.137,00$ \\
Paraguaçu & $369.843,00$ \\
Poço Fundo & $197.734,00$ \\
Santa Rita de Caldas & $134.311,00$ \\
São João da Mata & $35.636,00$ \\
TOTAL & $\mathbf{4 1 6 . 5 1 7 , 0 0}$ \\
\hline
\end{tabular}

Fonte - IBGE, 2014.

A análise dos mais de 4 bilhões de reais do PIB na região é melhor visualizada quando divide-se pelos setores censitários, em forma de renda per capita (Figura 4).

A figura 4 contrastando com a figura 3, evidência que as maiores rendas per capita não estão na cidade, mas sim no campo. Isso deve-se, a participação forte participação agropecuária na economia regional, sobretudo do café. Essa desconcentração da renda da cidade, e dispersa no campo indica a forte ruralidade do ponto de vista econômico da região, que tem sua relação na vida e cotidiano dos municípios.

O Sul de Minas Gerais é conhecido nacional e internacionalmente pela importância econômica que tem na produção de café. Esta, sem dúvida, tem sido uma importante atividade que dinamiza a economia sub-regional e tem peso considerável no Produto Interno Bruto, além de condicionar certo dinamismo populacional nas localidades produtoras, com a contratação de trabalhadores temporários para a colheita do produto. Conforme a tabela 3, Alfenas é o município 
com a maior produção de café em toneladas (24.243) e com o maior valor de produção mais de 189 milhões de reais. Porém, o município com maior área colhida é Machado, 12.850 ha, em comparação com 10.775 de Alfenas. O município que menos produz é Santa Rita de Caldas, que contabiliza 342 toneladas, 190 de área colhida para um valor de $\mathrm{R} \$ 2.702 .000,00$.

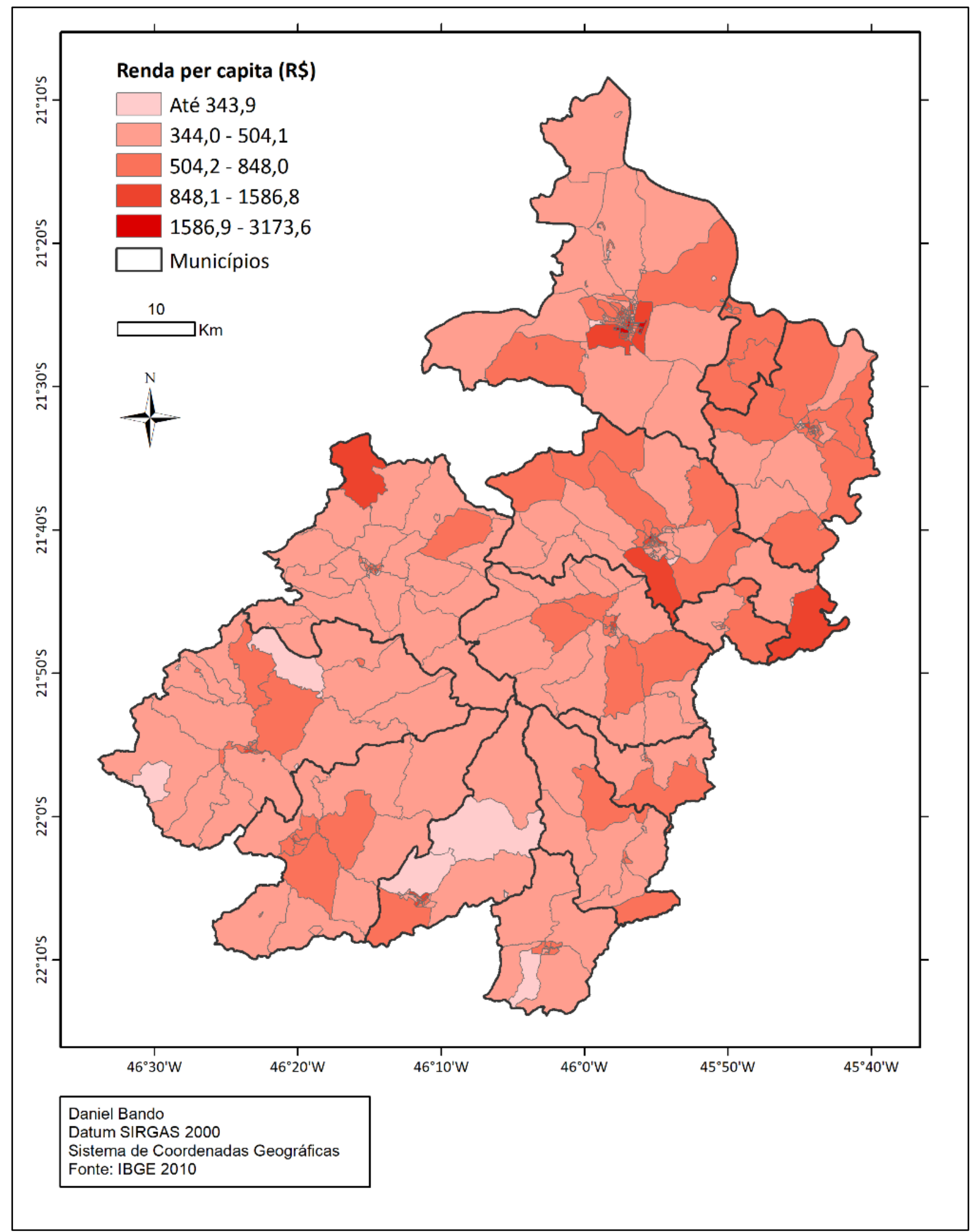

Figura 4 - Renda per capita dos municípios que compõem a APA do rio Machado, 2010. 
Tabela 3 - Produção de Café da APA do Rio Machado-MG, 2016.

\begin{tabular}{lccc}
\hline \multicolumn{1}{c}{ Produtores de Café } & $\begin{array}{c}\text { Quantidade produzida } \\
\text { (Em toneladas) }\end{array}$ & $\begin{array}{c}\text { Área colhida } \\
\text { (Hectares) }\end{array}$ & $\begin{array}{c}\text { Valor da Produção } \\
\text { (Mil R\$) }\end{array}$ \\
\hline Alfenas & 24.243 & 10.775 & $189.074,00$ \\
Caldas & 858 & 650 & $6.864,00$ \\
Campestre & 16.620 & 9.000 & $134.622,00$ \\
Carvalhópolis & 3.085 & 1.714 & $23.494,00$ \\
Congonhal & 525 & 350 & $4.260,00$ \\
Espírito Santo do Dourado & 1.354 & 1.188 & $10.986,00$ \\
Fama & 2.016 & 1.200 & $13.709,00$ \\
Machado & 23.901 & 12.850 & $167.307,00$ \\
Paraguaçu & 15.840 & 8.000 & $123.552,00$ \\
Poço Fundo & 8.824 & 6.267 & $67.018,00$ \\
Santa Rita de Caldas & 342 & 190 & $2.702,00$ \\
São João da Mata & 1.104 & 800 & $8.722,00$ \\
\multicolumn{1}{r}{ TOTAL } & $\mathbf{9 8 . 7 1 2}$ & $\mathbf{5 2 . 9 8 4}$ & $\mathbf{7 5 2 . 2 8 3 , 0 0}$ \\
\hline
\end{tabular}

Fonte - IBGE, Produção Agrícola 2016.

A área colhida de café em 2016 foi de 52.984 hectares, mostrando a territorialização dessa atividade agrícola, que detém tanto pequenas como grandes propriedades, familiares e empresariais, orgânicas e convencionais, e para o mercado interno e externo. O valor da produção em grãos, passou de 750 milhões de reais em 2016, sem contar os processos de transformação, como secagem, torra, moagem e embalagem, que agrega mais valor na economia regional, ou seja, só esse valor representa quase $20 \%$ do PIB dos municípios da APA.

Após o café, a produção de milho se destaca na área colhida e suas repercussão na economia regional. (Tabela 4).

Tabela 4 - Produção de Milho da APA do Rio Machado-MG, 2016.

\begin{tabular}{lccc}
\hline Produtores de Milho & $\begin{array}{c}\text { Quantidade produzida } \\
\text { (Toneladas) }\end{array}$ & $\begin{array}{c}\text { Área colhida } \\
\text { (hectares) }\end{array}$ & $\begin{array}{c}\text { Valor da Produção (Mil } \\
\text { R\$) }\end{array}$ \\
\hline Alfenas & 54.000 & 7.800 & $35.532,00$ \\
Caldas & 20.800 & 3.200 & $14.144,00$ \\
Campestre & 18.000 & 2.500 & $11.700,00$ \\
Carvalhópolis & 940 & 160 & 658,00 \\
Congonhal & 1.200 & 200 & 892,00 \\
Espírito Santo do & 3.672 & 680 & $2.730,00$ \\
Dourado & 2.400 & 400 & $1.560,00$ \\
Fama & 6.000 & 1.000 & $4.200,00$ \\
Ipuiúna & 38.880 & 6.600 & $24.840,00$ \\
Machado & 28.464 & 4.100 & $20.549,00$ \\
Paraguaçu & 4.608 & 810 & $2.903,00$ \\
Poço Fundo & 17.820 & 2.700 & $12.830,00$ \\
Santa Rita de Caldas & 3.822 & 585 & $2.510,00$ \\
São João da Mata & $\mathbf{2 0 0 . 6 0 6}$ & $\mathbf{3 0 . 7 3 5}$ & $\mathbf{1 3 2 . 5 3 8 , 0 0}$ \\
TOTAL & &
\end{tabular}

Fonte - IBGE, Produção Agrícola 2016. 
Conforme podemos observar na tabela 4, a produção de Milho é realizada por todos os municípios da APA do Rio Machado. Com destaque para Alfenas, que produziu 54.000 toneladas, com um valor de produção de mais de 35 milhões de reais e para Machado, que produziu 38.800 toneladas para um valor de produção de quase 25 milhões de reais. O município que menos produz Milho é Carvalhópolis, que produziu 940 toneladas para um valor de produção de R\$ 658.000,00.

Essa atividade agrícola está atrelada a alimentação animal, que tem grande importância na região, principalmente o gado leiteiro, e também para alimentação humana. Quanto a alimentos de subsistência urbana, destacam-se a batata e o feijão (tabela 5 e 6).

Tabela 5 - Produção de Batata-Inglesa da APA do Rio Machado-MG, 2016.

\begin{tabular}{lccc}
\hline $\begin{array}{c}\text { Produtores de } \\
\text { Batata-Inglesa }\end{array}$ & $\begin{array}{c}\text { Quantidade produzida } \\
\text { (Toneladas) }\end{array}$ & $\begin{array}{c}\text { Área colhida } \\
\text { (hectares) }\end{array}$ & $\begin{array}{c}\text { Valor da Produção } \\
\text { (Mil R\$) }\end{array}$ \\
\hline Alfenas & 5.000 & 200 & $6.500,00$ \\
Caldas & 14.850 & 550 & $25.650,00$ \\
Campestre & 10.750 & 400 & $16.600,00$ \\
Congonhal & 4.500 & 150 & $6.372,00$ \\
Espírito Santo do & 14.850 & 550 & $23.069,00$ \\
Dourado & 104.000 & 3.200 & $192.400,00$ \\
Ipuiúna & 3.300 & 110 & $2.760,00$ \\
Paraguaçu & 440 & 22 & 567,00 \\
Poço Fundo & 27.000 & 1000 & $44.550,00$ \\
Santa Rita de Caldas & 5.130 & 190 & $7.371,00$ \\
São João da Mata & $\mathbf{1 8 9 . 8 2 0}$ & $\mathbf{6 . 3 7 2}$ & $\mathbf{3 2 5 . 8 3 9 , 0 0}$ \\
TOTAL & & & \\
\hline
\end{tabular}

Fonte - IBGE, Produção Agrícola 2016.

Conforme pode-se observar na tabela 5, o município responsável pela maior produção de Batata-Inglesa é Ipuiúna, que contabiliza 104.00 toneladas em uma área colhida e 3.200 ha para um valor de pouco mais de 192 milhões de reais. Se compararmos com os demais municípios podemos notar a discrepância entre Ipuiúna com os outros. Onde o segundo maior produtor é responsável por apenas 27.000 toneladas em 1.000 ha para um valor de mais de 44 milhões de reais. O município que menos produz é Poço Fundo, que contabiliza 440 toneladas em 22 ha de área colhida para um valor $\mathrm{R} \$ 567.000,00$.

Ipuiúna é caracteriza pela forte presença de pequenas propriedades familiares, isso justifica a atividade de subsistência, não estando articulada com uma produção de commodities e, se comparado com a área de cultivos do café e milho, a produção de alimentos de subsistência é muito inferior (tabela 6). 
Tabela 6 - Produção de Feijão da APA do Rio Machado-MG, 2016.

\begin{tabular}{lccc}
\hline \multicolumn{1}{c}{ Produtores de Feijão } & $\begin{array}{c}\text { Quantidade produzida } \\
\text { (Toneladas) }\end{array}$ & $\begin{array}{c}\text { Área colhida } \\
\text { (hectares) }\end{array}$ & $\begin{array}{c}\text { Valor da Produção } \\
\text { (Mil R\$) }\end{array}$ \\
\hline Alfenas & 4.800 & 4.600 & $26.702,00$ \\
Caldas & 775 & 650 & $3.113,00$ \\
Campestre & 1.560 & 1.300 & $6.264,00$ \\
Carvalhópolis & 105 & 107 & 530,00 \\
Congonhal & 42 & 35 & 167,00 \\
Espírito Santo do Dourado & 181 & 180 & 704,00 \\
Fama & 72 & 30 & 342,00 \\
Ipuiúna & 620 & 400 & $2.358,00$ \\
Machado & 750 & 700 & $2.426,00$ \\
Paraguaçu & 2.475 & 1.630 & $8.820,00$ \\
Poço Fundo & 72 & 92 & 301,00 \\
Santa Rita de Caldas & 952 & 700 & $3.683,00$ \\
São João da Mata & 21 & 21 & 94,00 \\
TOTAL & $\mathbf{1 2 . 4 2 5}$ & $\mathbf{1 0 . 4 4 5}$ & $\mathbf{8 3 . 5 0 4 , 0 0}$ \\
\hline
\end{tabular}

Fonte - IBGE, Produção Agrícola 2016.

Conforme podemos observar na tabela 6, a produção de Feijão é realizada por todos os municípios da APA do Rio Machado. Com Destaque para Alfenas que produziu 4.800 toneladas em uma área colhida de 4.600 ha, com um valor de mais de 26 milhões de reais e também Paraguaçu, que produziu 2.475 toneladas em uma área colhida de 1.630 ha, com um valor de quase 9 milhões de reais. Já o município que menos produz feijão é São João da Mata, onde foram contabilizadas 21 toneladas em 21 ha de área colhida, com um valor de $\mathrm{R} \$ 94.000,00$.

Após essas análises, constata-se a centralidade na relação cidade-campo em Alfenas, como o município com o maior valor da produção de café na região, concentrando capital e importância no agronegócio cafeeiro e também na geração de empregos, conforme demostra a população economicamente ativa.

Desse modo, é importante analisar o comportamento interurbano da renda no campo e na cidade, para verificar possíveis concentrações e segregações socioespaciais (Figura 5 e 6).

Conforme observa-se na figura 5, as maiores rendas per capita estão concentradas no perímetro urbano, a riqueza gerada nas fazendas de café são drenadas para a área central do município. Inclusive com bairros rurais e aglomerados rurais apresentando índices inferiores a 1 salário mínimo por pessoa, ou seja, uma contradição latente entre a riqueza gerada pelo agronegócio contrastando com a pobreza rural. Na área urbana de Alfenas, pode-se analisar o processo semelhante na área rural, uma segregação socioespacial (Figura 6).

A figura 6 apresenta os bairros e suas rendas per capita, evidenciando uma segregação econômica, na zona leste da cidade, estão as maiores rendas, juntamente com o bairro central, ou seja, em cidades médias, a concentração da elite econômica ainda está situada no centro da cidade e em 
bairros porco afastados do centro, como Jardim Aeroporto, Jardim São Lucas e Alto do Aeroporto. Os bairros situados a oeste, como Pinheirinho e Santa Clara, e a norte como Primavera e Vila Promessa, apresentam as menores rendas per capita, merecendo atenção aos governos públicos, para melhorias socioeconômicas.

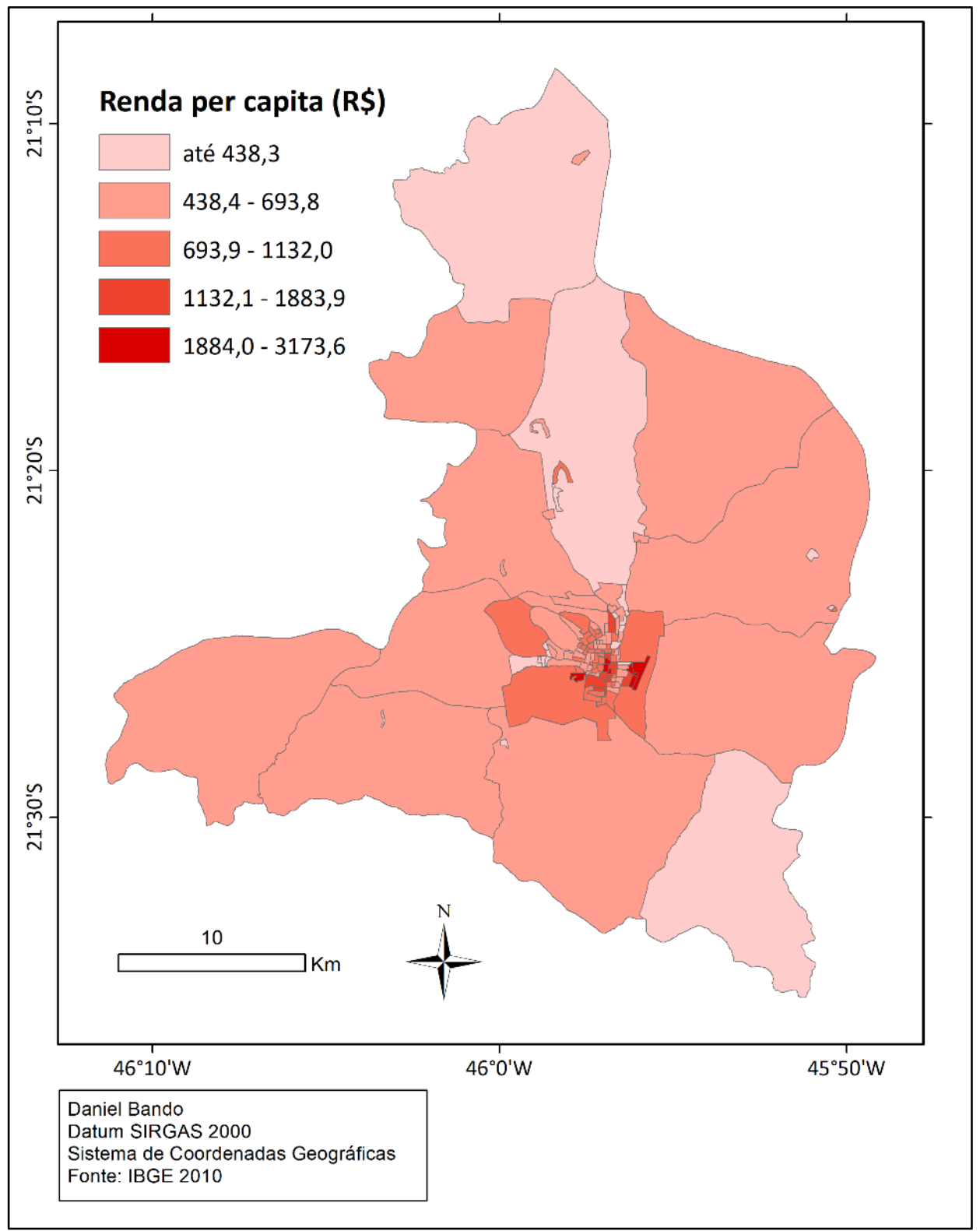

Figura 5 - Renda per capita por setores censitários no município de Alfenas -MG, 2010. 


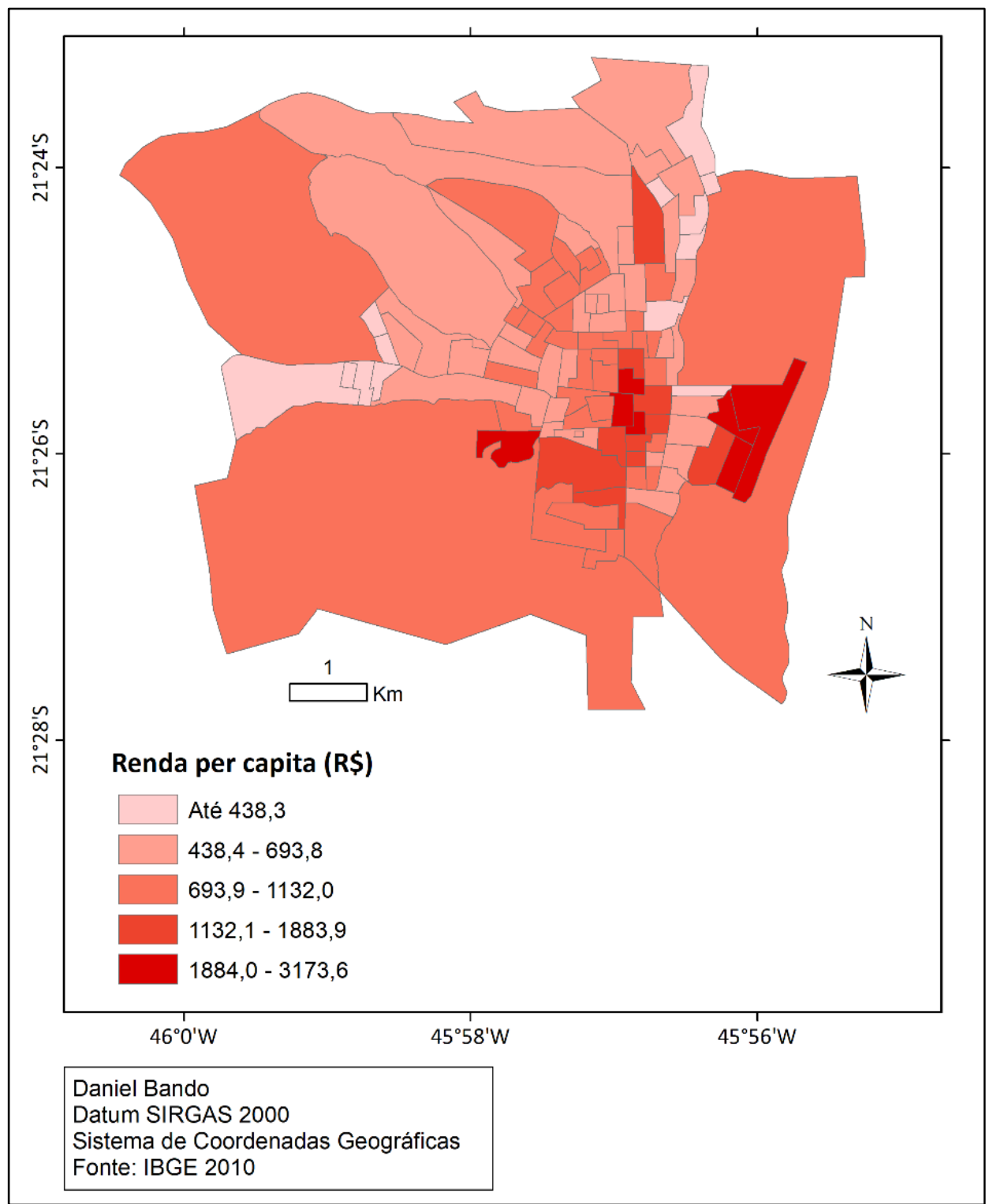

Figura 6 - Renda per capita no município de Alfenas na área urbana, 2010.

\section{CONSIDERAÇÕES FINAIS}

A APA do rio Machado apresenta situações especiais no que tange as atividades econômicas, devido à forte ruralidade na região, principalmente pelo agronegócio cafeeiro, o campo e a cidade expõem interações espaciais direcionadas a essa função. A região da APA é composta por uma cidade média em consolidação, Alfenas, e 11 municípios de pequeno porte, cuja função econômica está vinculada ao campo.

É necessário aos órgãos de planejamento e fiscalização, que verifiquem os impactos da atividade agropecuária, principalmente o agronegócio cafeeiro nos mananciais e áreas de nascentes, pois as áreas plantadas e colhidas dessa cultura agrícolas estão presentes em todos municípios e áreas da APA. 


\section{REFERÊNCIAS}

ALVES, F. D. Cidades pequenas no sul de Minas Gerais: ruralidades presentes no território. In: FERREIRA, M. M.; VALE, A. R. (Orgs.) Dinâmicas geográficas no sul de Minas Gerais. Curitiba: Appris, 2018. p. 107-127.

ALVES, F. D.; VALE, A. R. A relação campo-cidade e suas leituras no espaço. ACTA Geográfica, Boa Vista, Ed. Esp. Geografia Agrária, p. 33-41, 2013.

CORRÊA, R. L. Interações Espaciais. In. CASTRO, I. E.. GOMES, P. C.; CORRÊA, R. L. (Org.) Explorações Geográficas. Rio de Janeiro: Bertrand Brasil, 1997. p. 279-318.

CORRÊA, R. L. Construindo o conceito de cidade média. In: SPOSITO, M. E. B. (Org.) Cidades médias: espaços em transição. São Paulo: Expressão Popular, 2007. p. 23-33.

EVANGELISTA, A. W. P.; CARVALHO, L. G.; SEDIYAMA, G. C. Zoneamento climático associado ao potencial produtivo da cultura do café no Estado de Minas Gerais. Revista Brasileira de Engenharia Agrícola e Ambiental, Campina Grande, v. 6, n. 3, p. 445-452, 2002.

FILETTO, F.; ALENCAR, E. A. Introdução e expansão do café na região sul de Minas Gerais. Organizações Rurais \& Agroindustriais, Lavras, v. 3, n. 1, p. 1-10, 2001.

IBGE - INSTITUTO BRASILEIRO DE GEOGRAFIA E ESTATÍSTICA. Região de Influência das Cidades - 2007. Disponível em: <http://www.ibge.gov.br/home/geociencias/geografia. Acesso em: 23 abr. 2018.

SANTOS, M. A natureza do espaço: Técnica e tempo. Razão e emoção. 4. ed. São Paulo: EDUSP, 2006. 260p.

SANTOS, M. Espaço e Método. 5. ed. São Paulo: EDUSP, 2014. 120p.

SPOSITO, M. E. B. Cidades Médias: reestruturação das cidades e reestruturação urbana. In: SPOSITO, M. E. B. (Org.) Cidades médias: espaços em transição. São Paulo: Expressão Popular, 2007. p. 233-253. 